\title{
Cooperação Tecnológica Universidade-Empresa para Eficiência Energética: um Estudo de Caso
}

\author{
Andréa Paula Segatto-Mendes \\ Nathan Mendes
}

\section{RESUMO}

O objetivo central deste artigo é apresentar o desenvolvimento e as características de um relacionamento interinstitucional, visando ao aperfeiçoamento da tecnologia existente em redução de consumo de energia em sistemas domésticos de refrigeração e também a adequação do caso estudado aos pressupostos mais recentes do desenvolvimento do modelo da Tripla Hélice de Etzkowitz. O estudo refere-se a cooperações tecnológicas entre universidades e empresas e à apresentação de uma experiência de sucesso, em que a atuação conjunta de instituições distintas conduziu a ganhos tecnológicos para ambas as partes. Os dados foram levantados por meio de entrevistas individuais em profundidade com os coordenadores da pesquisa na universidade e na empresa. Os resultados obtidos demonstraram não apenas a eficiência do trabalho conjunto, mas também o sucesso da atuação cooperativa e a identificação, na prática, de novos posicionamentos levantados em estudos recentes. Desse modo, pode-se perceber por meio do estudo da experiência dessas instituições em uma cooperação tecnológica, a produtividade e eficiência do trabalho cooperativo universidadeempresa e suas possibilidades de contribuição ao desenvolvimento tecnológico do País.

Palavras-chave: inovação tecnológica; cooperação universidade-empresa; eficiência energética.

\begin{abstract}
The central aim of this article is to demonstrate the development and characteristics of an interinstitutional relationship with a view to perfecting existing technology in reducing the consumption of energy in household refrigerators and also to show the adequacy of the case studied for the most recent preconceived ideas concerning the development of Etzkowitz's Triple Helix. The study refers to the technological cooperation between universities and industries and the presentation of a successful experience in which the joint action of individual institutions led to technological gains for both parties. The data was collected from individual in depth interviews with the research coordinators at the both company and the university. The results obtained showed not only the efficiency of the joint research but also the success of the cooperation and the identification of the practice of new positions raised in recent studies. Thus, by studying the experience of these institutions in technological cooperation, we can see that the productivity and efficiency of the cooperation between the university and the company open up possibilities for contributing to the technological development of the country.
\end{abstract}

Key words: technological innovation; cooperation between university and company; energy efficiency. 


\section{INTRODUÇÃO}

A relevância do processo de inovação tecnológica em empresa tem-se refletido no desempenho econômico dos países em que elas se inserem, uma vez que esse desempenho se apóia em grande parte no desenvolvimento e utilização das tecnologias de informação e comunicação (OECD, 2000); juntamente com esse fator, autores como Gaynor (2002), Rogers (2003), Jonhston Jr. e Bate (2003) defendem a importância estratégica do processo de inovação para as próprias empresas. A relação entre a capacidade competitiva de empresas e países com o conhecimento e sua gestão tem tornado cada vez mais evidente a importância de estruturas como as de pesquisas científicas e tecnológicas, mediante parcerias entre universidades e empresas. Tais parcerias contribuem para o desenvolvimento da ciência, suas aplicações e a apropriação das inovações daí resultantes, o que, a partir do deslocamento do paradigma da sociedade industrial para a sociedade do conhecimento (Fugino, Stal, \& Plonski, 1999), pode ser visto como fator crucial no crescimento econômico, social e cultural de nações e organizações.

Além disso, como colocam Gomes e Kruglianskas (2005), a competitividade do cenário atual posiciona a gestão da inovação como uma das mais relevantes práticas administrativas para o sucesso empresarial. A esse discurso alia-se a percepção de Vedovello $(1997,1998)$ que cita a existência de esforços e iniciativas de cooperação entre organizações voltadas para atividades de pesquisa e desenvolvimento (P\&D) nos últimos anos, apesar da ausência de políticas de estímulo ao desenvolvimento tecnológico no país nas últimas décadas (Alem, Barros, \& Giambiagi, 2002; Lastres, 1997).

Essa preocupação tem unido universidades e empresas; em quase todos os países, a aproximação entre essas instituições já é uma realidade e tem-se intensificado nos últimos 20 anos. Uma das maiores responsáveis por isso é a revolução tecnológica em curso, que traz uma obsolescência cada vez mais rápida de processos e produtos. Desse modo, novas tecnologias dão origem a novos setores industriais que são marcados pela forte incorporação de conhecimentos científicos e técnicos (Stal, 1997). Além disso, no que se refere a empresas multinacionais e suas subsidiárias, Boehe e Zawislak (2005) comentam que essas empresas podem evitar que suas subsidiárias estabeleçam interações com organizações locais para realização de pesquisa por receio de que seu conhecimento e tecnologias estratégicas sejam transferidos a seus concorrentes; no entanto os autores complementam: "Quando houver parceiros locais altamente qualificados, entretanto, cooperações tecnológicas podem ajudar a subsidiária a 
adquirir conhecimento específico dos parceiros externos. Esse conhecimento específico adquirido localmente pode ser alavancado globalmente por meio das outras subsidiárias" (p. 2).

Adicionalmente, as relações entre universidades e empresas, além de facilitar a melhor difusão e transferência de novos conhecimentos, podem promover a criação de empregos e o aumento de renda quando bem-sucedidas, o que representa enormes ganhos para essas instituições (Chaimovich, 1999). Assim, esse arranjo interinstitucional, que visa à pesquisa conjunta, apresenta-se como importante modelo de desenvolvimento, tanto de universidades e empresas, como do país. No entanto o Brasil não possui ainda uma elevada utilização desse tipo de arranjo, o que tem levado autores a citar esse baixo nível de interação como um dos principais fatores para o baixo índice de inovações geradas no país (Levy, 2005; Pereira \& Kuglianskas, 2005; Stal \& Fujino, 2005).

Este trabalho refere-se a cooperações entre universidade e empresas e à apresentação e descrição de uma experiência de sucesso, em que a atuação conjunta de instituições distintas conduziu a maiores ganhos tecnológicos para ambas as partes. O objetivo central é demonstrar o desenvolvimento e as características de um relacionamento interinstitucional com o objetivo comum de aperfeiçoar a tecnologia existente em sistemas de redução de consumo de energia em sistemas domésticos de refrigeração e também a adequação do caso aos pressupostos mais recentes do desenvolvimento do modelo da Tripla Hélice de Etzkowitz.

Nesse sentido, outros objetivos se colocam, como a demonstração do crescimento acelerado de um laboratório jovem em uma instituição privada (Pontifícia Universidade Católica do Paraná, PUCPR), que buscou mecanismos diferenciados para sua expansão, acreditando nas cooperações entre universidades e empresas, como um dos propulsores de seu desenvolvimento; a verificação de novas peculiaridades das cooperações U-E, apontadas por Etzkowitz e Leydesdorf (2000); bem como a apresentação dos resultados obtidos pelo laboratório e pela empresa Electrolux do Brasil em função de suas necessidades individuais.

\section{As Cooperações Universidade-EMpresa}

Segundo Etzkowitz (2003, p.299), o termo "inovação tem tomado um sentido mais amplo nos anos recentes. Mais do que o desenvolvimento de novos produtos nas empresas, é também a criação de novos arranjos entre as esferas institucionais que propiciam as condições para a inovação". Nesse sentido, as cooperações 
universidade-empresa representam importante instrumento na geração de ciência e tecnologia em um país, porquanto, ao repartir custos e riscos entre as duas instituições, a pesquisa cooperativa permite maior investimento na geração de novas tecnologias voltadas a produtos e processos que garantam maior competitividade às organizações e a ampliação do conhecimento científico da nação (Segatto-Mendes, 2001).

A vinculação entre a universidade e as empresas não ocorre de um momento para o outro; é processo contínuo em que determinados estágios devem ocorrer. Segundo Sbragia (1994), estes estágios são em número de três. O primeiro seria aquele em que surge a disposição a cooperar e as partes demonstram esta disposição, ocorrendo encontros entre os participantes no sentido de buscar a cooperação. O segundo estágio seria o momento em que ocorre o intercâmbio de informações. A postura é positiva e as partes procuram trocar informações, mas poucos resultados são obtidos. Nesta etapa, algumas vezes, as universidades elaboram manuais que fornecem as suas possibilidades e seus profissionais ou catálogos, com as tecnologias e serviços à disposição das empresas. No terceiro estágio é que, então, a cooperação se torna efetiva. Neste caso, a busca de informação dos setores participantes é constante e já existe consciência dos benefícios concretos que a integração irá promover.

As relações interorganizacionais como as cooperações U-E podem estruturarse de maneiras diversas. Segundo Hall (2004), esses relacionamentos podem apresentar diferentes graus de formalização e padronização, freqüência de transações, relevância percebida por cada parte e graus diversos de simetria informacional e transacional. Uma questão polêmica na discussão da cooperação universidade-empresa refere-se ao adequado papel dos governos federal, estadual ou municipal, nesse processo. Sobre esse tema Plonski (1995) cita o trabalho Ciência e Tecnologia no Desenvolvimento Futuro da América Latina, apresentado por Jorge Sábato e Natalio Botana na World Order Models Conference, realizada em Bellagio, na Itália, em setembro de 1968, onde os autores discutem o desenvolvimento da América latina e o papel da ciência e da tecnologia nesse desenvolvimento, incluindo o instrumento cooperação universidade-empresa. Para eles seria importante uma ação múltipla e coordenada de três elementos, o governo, a estrutura produtiva e a infra-estrutura científico-tecnológica, fundamentais para o alcance de maior desenvolvimento, por meio desse sistema. Eles descrevem graficamente essa relação na forma de um triângulo (conhecido como o Triângulo de Sábato), em que o vértice superior é ocupado pelo governo e os da base pelos outros dois elementos.

Novas figuras foram desenvolvidas a partir desse modelo geométrico, cuja representação é feita por elaboradas redes, cada vez mais complexas, como, por 
exemplo, o modelo na forma de um tetraedro, desenvolvido pelo prof. Jorge Domingo Petrilho (Reitor da Universidade Nacional Mar del Plata, na Argentina), onde é incluído como quarto vértice, o setor financeiro. Outro exemplo é o Modelo da Hélice Tripla citado por Etzkowitz e Leydesdorff (1997a), em que são definidas quatro dimensões: transformação interna em cada hélice, influência na outra hélice, criação de nova cobertura de redes e organizações trilaterais e efeito recursivo dessas mudanças sobre as esferas institucionais. Assim, a colaboração crescente entre as esferas pública, privada e acadêmica, por esse modelo, gera a espiral de elos nos diversos estágios do processo de inovação. Acerca disso como colocam Flores e Segatto-Mendes (2005, p. 5):

Dentro desta realidade socioeconômica, a interação universidade-empresagoverno deve ser idealizada e planejada cuidadosamente. Neste constructo estão incluídas a vontade política da administração central da universidade e institutos de pesquisa; a vocação e convicção do corpo docente e de pesquisadores; e uma estrutura de gestão em moldes empresariais, com a finalidade de funcionar como veículo de ligação institucional entre academia, mercado e governo; e a consciência política do governo, principalmente local.

Os recentes estudos de Etzkowitz tem como um de seus diferenciais a percepção de maior aproximação entre universidades e empresas, atenuando os reflexos da natureza distinta comentada por Plonski (1994). Nesse sentido, Etzkowitz (2003, p. 302) coloca: "A base do conhecimento e seu papel na inovação pode ser explicado em termos das mudanças nas relações entre universidade, indústria e governo (veja Figura 1)". Essa figura apresenta melhor compreensão do desenvolvimento da chamada tripla hélice.

\section{Figura 1: Do Estadista e Laissez-Faire a Tripla Hélice}
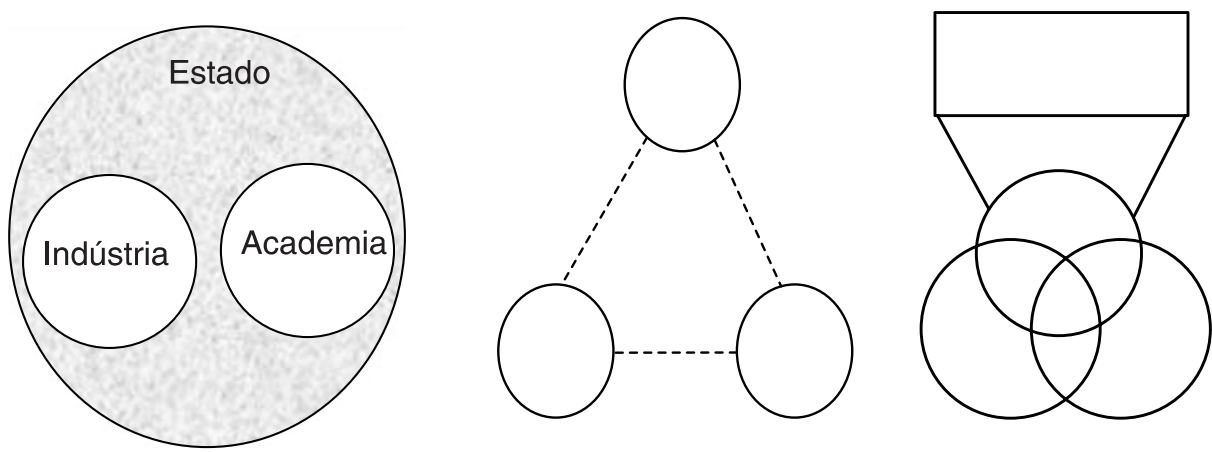

Fonte: adaptado de Etzkowitz e Leydesdorff (2000, p. 4).

Segundo Noveli (2006), a primeira sistematização da Figura 1 apresenta o governo englobando as universidades e as empresas, direcionando as relações de 
cooperação a serem estabelecidas. A segunda (o Triângulo de Sábato) estabelece a clara separação institucional entre as esferas; no entanto, estando o "governo no vértice superior do triângulo, ele mantém o papel de incentivador da relação, o que possibilita sua atuação como direcionador do desenvolvimento" (p. 22). Por fim, a terceira esquematização segundo Etzkowitz e Leydesdorff (2000, p.111) "está gerando uma infra-estrutura de conhecimento em termos de sobreposição das esferas institucionais, com cada uma desempenhando o papel da outra e com organizações híbridas emergindo destas interfaces". Dois fatores caracterizam principalmente o desenvolvimento do modelo das cooperações até a Tripla Hélice: a capitalização do conhecimento e a busca do desenvolvimento regional pela universidade como terceira missão.

A capitalização do conhecimento implica a transformação do conhecimento em "capital social por acadêmicos, envolvendo setores da universidade tais como departamentos de ciência básica, daqui em diante, relativamente não envolvidos com a indústria" (Etzkowitz, 1998, p. 825). E por outro lado, Etzkowitz (1998, p. 825) destaca "a emergência da universidade como um participante liderando o desenvolvimento econômico de sua região".

Deve-se salientar que a capitalização do conhecimento pode ser fruto da ação dos pesquisadores empreendedores. Nesse sentido, podem desenvolver suas próprias empresas ou mesmo se relacionarem diretamente com a indústria, articulando-se sem a necessidade de um agente intermediário. (Etzkowitz 1998). Além disso, a percepção da universidade, enquanto agente de desenvolvimento econômico regional, apresenta-se clara dentro de um contexto em que o conhecimento se tem tornado um ativo cada vez mais importante, principalmente ao se considerar que as universidades são reconhecidamente uma fonte de geração de novos conhecimentos. De acordo com Etzkowitz e Leydesdorff (1997b, p. 1): "canalizar fluxos de conhecimento em novas fontes de inovação tecnológica temse tornado uma tarefa acadêmica, mudando a estrutura e função da universidade".

Considerando o contexto brasileiro, Etzkowitz, Mello e Almeida (2005) ao analisar evidências empíricas por eles levantadas e que apoiariam o modelo de tripla hélice no Brasil, argumentam: "O Brasil tem atravessado uma transição de um sistema de inovação de cima para baixo para um modelo de tripla hélice, com a universidade desempenhando um papel expandido" (p.413). Ou seja, já poderiam ser identificadas em processos cooperativos brasileiros a absorção dos novos fatores salientados, assim como no restante da América Latina. Declara Sutz (1997, p. 12) em seu artigo sobre as relações universidade, indústria e governo na América Latina: "Hoje em dia as universidades são mais e mais consideradas tanto por empresas quanto por governos como instituições que seriam devotadas para o 'bem nacional' da competitividade econômica do que ao 'bem universal' 
do conhecimento. Na extensão que essa perspectiva vai sendo socialmente aceita, os limites entre academia e indústria se tornam apagados", o que reduziria as dificuldades presentes na natureza distinta das instituições parceiras.

Segundo Stal (1997, p.52), os países desenvolvidos estão alterando seus conceitos relativos às funções tradicionais da universidade, passando a considerar fatores como contratos de pesquisa com empresas e recursos financeiros resultantes desses acordos como indicadores de desempenho acadêmico. Em relação ao Brasil, a autora coloca que "os órgãos responsáveis pela política brasileira de C\&T estão atentos a essa tendência mundial e estão colocando à disposição das empresas instrumentos que possam promover um aumento dos investimentos privados em $\mathrm{P} \& \mathrm{D}$, seja internamente, seja por meio de consórcios com universidades e institutos de pesquisa".

\section{As Cooperações Universidade-Empresa no Contexto Brasileiro}

Um estudo desenvolvido por Segatto (1996), mediante a pesquisa sobre o processo de cooperação universidade-empresa no meio acadêmico brasileiro, permitiu identificar as principais variáveis apontadas como relevantes nos processos de cooperação no Brasil. A pesquisa identificou os principais motivadores, barreiras, facilitadores, elementos do processo de cooperação e satisfação resultante, apontados por entrevistados do meio acadêmico e empresarial, delineando assim, o perfil das cooperações tecnológicas universidade-empresa no Brasil.

O estudo realizado pela autora demonstrou que as principais motivações percebidas para as universidades pelos entrevistados foram as seguintes: recursos financeiros adicionais; recursos materiais adicionais; realização da função social da universidade; prestígio que será obtido pelo pesquisador; divulgação da imagem da universidade; obtenção de conhecimentos práticos sobre os problemas existentes; e incorporação de novas informações aos processos de ensino e pesquisa universitários. Todavia os fatores que apresentaram os maiores índices de concordância entre os entrevistados foram estes: realização da função social da universidade; obtenção de conhecimentos práticos sobre os problemas existentes; e incorporação de novas informações aos processos de ensino e pesquisa universitários.

Para as empresas, os motivadores encontrados foram os seguintes: acesso a recursos humanos altamente qualificados da universidade; redução dos custos e/ ou riscos envolvidos nos projetos de pesquisa $\&$ desenvolvimento; acesso aos mais novos conhecimentos desenvolvidos no meio acadêmico; identificação de alunos da instituição de ensino para recrutamento futuro; e resolução dos problemas técnicos que geraram a necessidade da pesquisa cooperativa. Os mais fortemente 
apontados foram o acesso a recursos humanos altamente qualificados da universidade e a resolução dos problemas técnicos que geraram a necessidade de tal pesquisa.

As principais barreiras levantadas pela pesquisa foram estas: burocracia universitária; duração muito longa do projeto e diferenças de nível de conhecimento entre as pessoas da universidade e da empresa envolvidas na cooperação. Já como facilitador do processo foram apontados os fundos governamentais de apoio à pesquisa. $\mathrm{O}$ estudo permitiu evidenciar que tanto universidades quanto empresas possuem agentes e/ou organizações que atuam no processo de cooperação, intermediando a relação das partes. Nas universidades, a totalidade das instituições selecionadas possui pelo menos uma organização para este fim específico e, nas empresas, a maioria sinalizou a existência de um agente.

Os principais instrumentos utilizados para a efetivação da cooperação apontados foram estes: relações pessoais informais, relações pessoais formais e acordos formais com alvo definido. Mas nenhum desses instrumentos concentrou mais de $50 \%$ dos projetos, tanto em universidades como em empresas, não identificando um instrumento dominante nos processos de pesquisa cooperativa. No entanto estudos posteriores apontaram que os contatos informais estão entre uma das mais significantes formas de relacionamento universidade-indústria válida mundialmente (Sutz, 2000). Além disso, outros estudos desenvolvidos por Vedovello $(1997,1998)$ classificaram as ligações que ocorrem em relações estabelecidas entre universidades e empresas como formais, informais e de recursos humanos, tanto para o desenvolvimento tecnológico quanto para outros fins, e que abarcam uma multiplicidade de relacionamentos que podem ocorrer entre esses atores, o que pode ou deve ser denominado cooperação tecnológica U-E (Raposo \& Serrasqueiro, 2005).

\section{A Transferência do Conhecimento}

A cooperação universidade-empresa não representa apenas o melhoramento tecnológico de produtos ou a criação de inovações; ela também significa uma troca de relacionamento em que a transferência do conhecimento entre as partes é muito importante, pois é por meio dessa transferência que ambas as partes poderão alcançar melhores resultados no processo de pesquisa. Por isso a transferência do conhecimento deve ser estruturada e encorajada desde o início do programa de pesquisa, para que uma comunicação freqüiente e aberta seja firmada entre os dois grupos. O sucesso na transmissão do conhecimento é fundamental para um adequado crescimento da base de conhecimento de ambos os participantes. 
Assim, é muito relevante a escolha do instrumento mais apropriado para o tipo de relação estabelecida entre as instituições, que deve contemplar o tipo de relacionamento por elas desejado e mais adequado aos objetivos propostos. Diversas classificações dos possíveis tipos de relação estabelecidas entre as universidades e empresas para pesquisa conjunta de tecnologia podem ser encontradas na literatura existente. Não existe consenso ou padrão rígido para os tipos de relações que devem ser estabelecidas, por ser uma relação que envolve grupos distintos de pessoas, vindos de condições diversas e pesquisando coisas novas. Novos estilos de trabalho deverão surgir naturalmente, à medida que o processo for exigindo estruturações mais complexas desses relacionamentos.

Além da definição do tipo de relação a ser desenvolvida, as universidades podem também desenvolver uma estrutura específica para auxiliá-las no processo de cooperação. Plonski (1999) conceitua essas estruturas como estruturas de interface, que seriam mecanismos institucionais desenvolvidos para promover e facilitar a cooperação. $\mathrm{O}$ autor cita os seguintes exemplos de estrutura de interface: escritórios de transferência de tecnologia; fundações conveniadas, estruturas empresariais com a missão de interagir com o segmento acadêmico; entidades de pesquisa sem fins lucrativos; entidades tecnológicas; entidades terceiras; e espaços institucionais diferenciados. Esses organismos estruturais seriam órgãos responsáveis por administrarem alguns aspectos da cooperação, como arrecadação, repasse e administração de recursos, divulgação das linhas de pesquisa da universidade, contato com as empresas parceiras potenciais, facilitação e manutenção da comunicação entre as partes (Segatto-Mendes \& Sbragia, 2002).

\section{Metodologia}

As pesquisas geralmente podem ser classificadas em três grandes grupos: exploratórias, descritivas e causais. De acordo com Selltiz, Wrigutsmann e Cook (1974): "os estudos formuladores ou exploratórios têm como objetivos de pesquisa a familiarização com o fenômeno ou conseguir nova compreensão deste, freqüentemente para poder criar um problema mais preciso de pesquisa ou criar novas hipóteses, sendo a principal acentuação a descoberta de idéias e instituições". Neste estudo foi realizada uma pesquisa exploratória, dado que foram buscadas informações por meio da investigação qualitativa do problema em tela, visando à descoberta de idéias e intuições sobre o tema.

O método adotado para o levantamento de dados foi o estudo de caso, que é indicado para estudos em que se trabalha com um fato específico que se considera típico ou ideal para explicar certa situação, sendo útil, quando se está 
em fase inicial de investigação ou buscando ampliar o conhecimento a respeito de certo tema.

O estudo de caso é um método em que o fenômeno é estudado e analisado em seu contexto real, buscando avaliar as decisões que foram tomadas, o porquê de determinadas atitudes adotadas e em que resultaram. Desse modo, as causas e conseqüências do fenômeno e seu desenvolvimento vão sendo esclarecidos, sempre dentro do momento e circunstâncias em que ocorreram.

Como o propósito básico deste estudo foi a busca de informações sobre o processo de cooperação universidade-empresa estabelecido entre o Laboratório de Sistemas Térmicos da PUCPR e a empresa Electrolux e suas contribuições para o crescimento das instituições participantes, fez-se necessário escolher um método que apresentasse idéias e sinais de como processo se efetivou e desenvolveu nas organizações envolvidas. Desse modo, optou-se pela utilização de entrevistas individuais em profundidade, direcionadas aos responsáveis pela pesquisa. As perguntas foram formuladas por meio de guia básico direcionado para os aspectos centrais do tema.

\section{A Cooperação lst - Electrolux}

\section{O Laboratório de Sistemas Térmicos (LST)}

A Pontifícia Universidade Católica do Paraná (PUCPR) é uma universidade situada na cidade de Curitiba, PR, criada em 14 de março de 1959 pelo então Arcebispo Metropolitano de Curitiba, Dom Manuel da Silveira D'Elboux. Reconhecida pelo Governo Federal em 17 de maio de 1960 (Decreto no 48.232), foi elevada pela Santa Sé à condição de pontifícia - título concedido às Universidades Católicas que tenham demonstrado, por vários anos, um acervo de serviços meritórios prestados à sociedade e à Igreja - em 8 de novembro de 1985.

O seu crescimento e desenvolvimento levaram à criação de novos cursos ao longo dessa jornada. Atualmente, a instituição possui 50 cursos de graduação e 9 de pós-graduação. O curso de Engenharia Mecânica foi criado em 1993, sendo portanto um curso jovem, que formou sua primeira turma em janeiro de 1998.

Em 1999 foi criado o Parque Tecnológico na PUCPR, com o objetivo tanto educacional como de prestação de serviço e criação da primeira estrutura de pesquisa para seus cursos. Esse parque engloba os cursos de Engenharia Mecânica, 
Civil, Mecatrônica, de Produção, Informática, Sanitária, Química, de Alimentos, de Computação e Elétrica, além de programas de pós-graduação em Engenharia Mecânica, Informática Aplicada e Produção e Sistemas; possui 78 laboratórios e uma área total de $16.835,87 \mathrm{~m}^{2}$.

O Departamento de Engenharia Mecânica da PUCPR mostrou sua tendência a pesquisa desde o princípio. O primeiro mestrado em Engenharia Mecânica do Paraná foi oferecido pelo departamento que, atualmente conta com 17 laboratórios de ensino e pesquisa em suas instalações, perfazendo uma área de $1500 \mathrm{~m}^{2}$.

Assim, em 1997, a partir da aquisição de uma câmara climatizada para apoio das aulas de laboratório da disciplina de Sistemas Térmicos do curso de graduação em Engenharia Mecânica, a docente responsável pela disciplina deu o início à formação de um novo laboratório, o LST (Laboratório de Sistemas Térmicos www.pucpr.br/lst). Em 1998, com a chegada de um novo docente ao Departamento de Engenharia Mecânica, que passou a formar equipe com a responsável pelo LST, iniciou-se a discussão sobre a possibilidade da realização de pesquisas para a expansão da estrutura e atividades do laboratório. Essa equipe se ampliou a partir da chegada de mais um professor no final de 1998.

Como os ambientes de desenvolvimento de produtos estão sujeitos ao ritmo imposto pelas exigências crescentes do mercado consumidor e da concorrência, percebeu-se a necessidade de agilizar o ciclo de projetos, por meio do emprego de ferramentas avançadas para ensaios de protótipos. Os produtos situados na vasta categoria de sistemas térmicos, em particular, apresentam a preocupação com a eficiência, que vem sendo amplificada nos últimos tempos pelos temores bem fundamentados quanto à crescente demanda de energia elétrica associada ao baixo crescimento de sua oferta.

Dentro desse contexto, foi construído, no LST, um sistema integrado para ensaios de avaliação de desempenho de sistemas térmicos. A parte principal desse sistema integrado é uma câmara climatizada de testes, capaz de simular ambientes diversos em seu interior, com temperatura e umidade relativa controlada. Consiste num compartimento de $2,5 \mathrm{~m} \times 3,5 \mathrm{~m} \times 3,0 \mathrm{~m}$, cujo fornecimento de ar nas condições desejadas é conseguido por meio de um sistema de ar condicionado composto de duas unidades condensadoras externas a Câmara, com capacidade total de 29800 $\mathrm{BTU} / \mathrm{h}$, que opera na faixa de $-10^{\circ} \mathrm{C}$ a $60^{\circ} \mathrm{C}$. $\mathrm{O}$ ar é conduzido por meio de dutos aos dampers, que possuem regulagem de inclinação de acordo com o fluxo necessário e que são controlados por um comando lógico programável (CLP). Estes insuflam o ar pelo teto; o retorno desse ar faz-se pelo piso. Como último estágio, existem duas resistências, que aquecem o ar de insuflamento, se necessário. 
Esta câmara climatizada representou recursos da ordem de US\$130.000; os professores acreditavam em maior potencial de utilização desse investimento. Ao mesmo tempo, o laboratório possuía necessidades relativas a recursos humanos e complementos referentes a material permanente. Desse modo, em 1998, sendo o consumo de energia uma área estratégica no Brasil, elaborou-se o projeto de pesquisa: Estudo de Redução de Consumo de Energia em Sistemas Domésticos de Refrigeração, que foi submetido ao programa RHAE (Recursos Humanos em Áreas Estratégicas) do CNPq e tendo seu início aprovado em fins de $1998 \mathrm{com}$ liberação de recursos em janeiro de 1999.

O projeto inicialmente foi programado para um período de dois anos. Seu principal objetivo era realizar estudos focados na redução de consumo de energia em sistemas domésticos refrigerados. Dentro deste estudo, duas linhas principais de atuação devem ser mencionadas. A primeira tratava de desenvolvimento e aperfeiçoamento do aparato experimental para a realização de ensaios de consumo de energia segundo a norma ISO. A segunda linha foi direcionada ao desenvolvimento de ferramentas computacionais, tanto para a aquisição de dados junto ao aparato experimental como para o desenvolvimento de um programa de simulação para análise de desempenho térmico e energético de produtos novos ou existentes.

A aprovação do projeto forneceu ao laboratório os recursos humanos qualificados necessários para impulsionar suas atividades por meio de três bolsas para engenheiros (DTI - Desenvolvimento Tecnológico Industrial) e quatro para estudantes de cursos de engenharia (ITI - Iniciação Tecnológica Industrial). As bolsas DTI's do CNPq são destinadas a possibilitar o fortalecimento da equipe; da instituição, por meio da agregação temporária de profissionais sem vínculo empregatício, necessários à execução do projeto. Por outro lado, as bolsas ITI's são destinadas a estimular o interesse pela pesquisa e desenvolvimento tecnológico em estudantes de $2^{\circ}$ e $3^{\circ}$ grau e de escolas técnicas, bem como de técnicos de nível médio com até três anos de formados, por meio de sua participação no projeto institucional. Nesse período, devido ao interesse da Electrolux do Brasil em estudos de redução de consumo de energia de seus produtos, iniciou-se uma troca de informações entre a empresa e o laboratório que culminaria no projeto de pesquisa cooperativa que será discutido.

Atualmente o LST ocupa uma área de $125 \mathrm{~m}^{2}$, dividido em duas unidades (LST1 e LST2); sua infra-estrutura, em termos de equipamento, soma um montante de cerca de US\$330.000. O LST pode ser representado pelo grupo de pesquisa cadastrado no CNPq que recebe o mesmo nome do laboratório e que, nos últimos dois anos, publicou 39 artigos em congressos nacionais e internacionais, $2 \mathrm{em}$ periódicos nacionais e 6 em periódicos internacionais especializados. O caso 
descrito neste artigo, fruto da colaboração entre PUCPR, CNPq/RHAE e Electrolux do Brasil, permitiu o desenvolvimento de pesquisas que promoveram consideráveis reduções no consumo de energia de refrigeradores domésticos pelo aperfeiçoamento tecnológico dos produtos, o que foi relevante não somente para a competitividade de uma das parceiras, como também conduziu a resultados para a universidade e para a economia nacional por meio da pesquisa na área de conservação de energia no setor residencial.

\section{A Pesquisa Cooperativa}

Em 1998, iniciaram-se as primeiras conversações entre o LST e a Electrolux do Brasil. O interesse da empresa em estudos de redução de consumo de energia para seus produtos foi motivação para as primeiras respostas ao contato estabelecido pela equipe, no sentido de apresentar as potencialidades de pesquisa existentes no LST. Assim, começaram-se os encontros para discussão de uma possível parceria de pesquisa entre as instituições.

Posteriormente, estabeleceu-se um período de troca de informações que conduziu à definição de temas prioritários para uma cooperação de pesquisa. Assim, iniciou-se a elaboração de um projeto; esse processo envolveu a reformulação dessas propostas por diversas vezes, para uma depuração das linhas de pesquisa contempladas no estudo. Além dos fatores relacionados diretamente à pesquisa, nessa fase também foram discutidos e rediscutidos diversos pontos relacionados às cláusulas contratuais do termo formal de cooperação como a propriedade intelectual dos resultados obtidos, o tipo e aprofundamento de informações a serem fornecidos pelas partes, o controle sobre atividades e outros. Essa fase correspondeu aproximadamente ao período de maio de 1998 a dezembro de 1999.

A PUCPR e Electrolux do Brasil já adotavam, como forma de interação para desenvolvimento de projetos, o estabelecimento de acordos formais via contrato entre as partes sem objetivos predefinidos (Programa Tecnópolis PUCPR). Ou seja, já havia um contrato maior entre as duas instituições que funcionava como contrato guarda-chuva: à medida que se criassem propostas de cooperação com laboratórios específicos da PUCPR, seriam elaborados termos aditivos específicos a cada pesquisa, que então fariam parte do contrato guarda-chuva. Antes do termo firmado com a PUCPR, já havia sido realizado outro termo de cooperação entre as instituições. Desse modo, concluída essa etapa de negociação e discussões para fechamento do primeiro projeto de cooperação de pesquisa apoiado pelo programa RHAE do CNPq (Ref. 610.041/98-3) e com o LST, elaborou-se um termo aditivo ao contrato formal, o qual teve seu início oficializado em janeiro de 2000. 
No termo aditivo relativo à cooperação entre PUCPR e Electrolux, cabia à empresa o fornecimento de equipamentos (refrigeradores, freezer, pacotes de carga térmica e cargas de refrigerante R-134a entre outros) e recursos financeiros liberados mensalmente. Ao LST/PUCPR, o desenvolvimento de pesquisas e a elaboração de relatórios periódicos. As atividades eram acompanhadas de reuniões freqüentes em que eram apresentados os resultados então obtidos e discutidos novos direcionamentos para a pesquisa. Nesse sentido, percebe-se a ocorrência da interação em diferentes formas que podem ser observadas aqui tanto em um dos papéis designados à empresa, que se configura num procedimento de financiamento de pesquisa científica da empresa para a universidade; como em um dos papéis designados à universidade, que pode ser descrito como prestação de serviço da universidade para a empresa. Essas diferentes formas de interação ocorrem conjuntamente com a atividade mais tradicional, que seria a pesquisa conjunta, que era realizada por meio do esforço conjunto com trocas de percepções, idéias, análises e resultados entre a equipe de pesquisa da empresa e a da universidade, ou seja, as atividades estabelecidas para a cooperação envolviam as três formas de interação concomitantemente.

Nesses dois anos de cooperação formal, uma vez que informalmente pode-se dizer que o processo se iniciou já em 1998, foram obtidos avanços significativos no trabalho de pesquisa. No entanto, nos primeiros meses, o desconhecimento entre as partes tornou o processo mais lento, havendo necessidade de se conhecer melhor para se confiar mais e também assim desenvolver uma linguagem comum e atitudes mais cooperativas. Isso caracterizou a ocorrência de uma situação conflituosa, uma vez que a dificuldade de comunicação passou a comprometer o andamento das atividades dentro do ritmo esperado. A situação se agravava pela presença de um coordenador na empresa que possuía como principal ferramenta de gestão e controle o estabelecimento de prazos que determinava de acordo com o que considerava ideal para a empresa, cobrando da equipe da universidade a adequação a um cronograma que não se adaptava ao processo de pesquisa, desenvolvido e realizado pelo laboratório.

No entanto, por fatores internos, esse coordenador, com formação superior em engenharia, foi transferido para outra unidade. O seu substituto, de formação técnica em tecnologia e superior em administração, trazia consigo, o que pode ser fruto de sua formação como gestor, uma consciência maior da natureza distinta do trabalho executado na empresa em relação às pesquisas desenvolvidas pela universidade, o que facilitou muito o andamento da cooperação, pois ele procurou consultar e respeitar as limitações de prazo estabelecidas pelo meio acadêmico.

O solucionamento desses conflitos se deu por meio de maior intensificação das relações, com maior número de encontros e diálogos informais por telefone e e- 
mail entre os coordenadores na empresa e na universidade. Esse procedimento promoveu uma intensificação do relacionamento entre as parceiras, permitindo o estabelecimento de maior confiança e entrosamento entre os participantes e o desenvolvimento de uma linguagem comum que muito facilitou a condução das atividades pelo restante da cooperação. Segundo os entrevistados, esse processo foi fundamental para que o projeto alcançasse o sucesso obtido.

Após esse período de adaptação, a pesquisa ganhou novo ritmo, conduzindo à elaboração dos programas SIAS (Software Integrado de Aquisição de Sinais) e FRIGUS (Programa de Simulação Térmica de Refrigeradores). O programa FRIGUS foi um dos primeiros resultados da pesquisa cooperativa. Ele foi desenvolvido por meio do método de diferenças finitas para simular, de forma integrada e simultânea, o gabinete e o circuito de refrigeração de produtos, permitindo análise do desempenho termoenergético. Grande vantagem desse sistema é poder ensaiar produtos de forma rápida com baixíssimo custo. Por exemplo, a alteração de volume interno, a espessura de parede ou o tipo de isolante térmico podem ser facilmente simulados; mas um ensaio experimental desses itens teria custo elevadíssimo para a empresa; logo, o uso do programa permite a realização de simulações com a mesma finalidade dos ensaios a um custo mínimo. Outra grande vantagem obtida com sua utilização é a possibilidade de analisar os produtos fora das condições de laboratório, isto é, em qualquer condição de temperatura e umidade.

Outro resultado obtido foi o SIAS, desenvolvido para realizar ensaios de consumo de energia de refrigeradores segundo procedimentos normalizados (ISO), o que facilitava e acelerava o processo de elaboração de relatórios. A necessidade desse procedimento também permitiu a preparação do LST para uma certificação futura.

Este trabalho de cooperação universidade-empresa permitiu o desenvolvimento de inovações tecnológicas incrementais, pois promoveu modificações que conduziram à melhoria de produtos existentes, além de permitir a transferência de conhecimento entre as partes, pois era necessário que a universidade conhecesse especificidades do produto, do sistema produtivo, da tecnologia utilizada e do mercado da parceira que interfeririam na aplicação de seu conhecimento altamente especializado na geração da inovação. Do mesmo modo, a empresa precisou aperfeiçoar suas competências para compreender e dominar o novo conhecimento gerado e, assim, absorver adequadamente a nova tecnologia. Nesse aspecto, é preciso ressaltar que o principal instrumento utilizado pela empresa foi a colocação de alguns de seus engenheiros em programas de mestrado da instituição parceira. Esses engenheiros desenvolviam seus estudos sob orientação do coordenador da pesquisa no LST. Assim, auxiliavam no desenvolvimento das 
atividades e realizavam suas dissertações dentro de questões que representavam partes da pesquisa como um todo. Percebe-se aqui também a ocorrência de outra forma de interação, além da pesquisa conjunta, isto é, dentro do próprio desenvolvimento da pesquisa em parceria, utilizou-se uma relação pessoal formal via pagamento do curso de mestrado na universidade, para que funcionários da empresa contribuíssem com a pesquisa por meio do desenvolvimento de suas dissertações.

Com isso, não somente se elevou a capacitação desses recursos humanos, como também se obteve maior facilidade de comunicação e fluidez na transferência da tecnologia, maior número de dissertações desenvolvidas na universidade e, conseqüentemente, maior número de publicações no programa de mestrado. Interessante ressaltar também que, como colocado pelo professor da PUCPR, a inclusão dos engenheiros da empresa no programa de mestrado aproximou mais os outros participantes da pesquisa da realidade da empresa e do objeto de estudo e elevou a motivação desses participantes, pois a condição dos engenheiros da empresa, também mestrandos, permitiu um entrosamento maior. Além disso, a pesquisa contribuiu com a meta de redução de consumo de energia do país; na época foi questão de altíssima relevância devido aos riscos de falta de energia elétrica pelos quais o país passava e que obrigou a nação a um programa de racionamento. A cooperação já resultou na conclusão do mestrado de cinco engenheiros da empresa. Atualmente, esse processo de geração e transferência de tecnologia em conjunto com a Electrolux conta ainda com dois engenheiros realizando o curso de mestrado em Engenharia Mecânica na PUCPR, com temas voltados às necessidades da empresa.

Considerando aspectos mais macroeconômicos, os entrevistados citaram também a contribuição dada à comunidade científica e ao mercado de trabalho brasileiro. A primeira, por ser uma área do conhecimento que dispõe de poucas referências bibliográficas e novas publicações foram obtidas com a pesquisa cooperativa. A segunda, em virtude da capacitação de mão-de-obra altamente especializada para o setor de refrigeração doméstica obtida com os trabalhos executados.

Em termos quantitativos para os resultados até a presente data, deve-se destacar o desenvolvimento de três programas computacionais (PAS, SIAS e FRIGUS), a realização de mais de 80 ensaios de consumo de energia e desenvolvimento, tanto de modelos matemáticos para simulação, como de novos evaporadores e de novas metodologias de ensaio, como, por exemplo, a utilização de fluxímetros de calor.

Em termos de documentação, foram elaborados três relatórios técnicos internos totalizando mais de 450 páginas, cinco dissertações de mestrado defendidas, além de artigos que foram elaborados e publicados em anais de eventos científicos. 
A análise conjunta dos três relatórios gerais, apresentados até hoje dentro deste convênio, conduz a um esboço dos resultados que a pesquisa vem alcançando, assim como a visualização do grande potencial de inovações e melhoramentos, no tocante à redução energética de produtos, a ser explorado.

\section{Considerações Finais}

A análise do processo de cooperação descrito permite a identificação de diversos aspectos levantados no referencial teórico apresentado neste estudo. Inicialmente, pode-se perceber a realização dos três estágios citados anteriormente. O primeiro estágio que se caracteriza pela disposição a cooperar e pelos primeiros encontros ocorreu em princípio de 1998, quando Electrolux e LST/PUCPR iniciaram as conversações iniciais para a discussão da possível parceira.

O segundo estágio ocorre entre maio de 1998 e dezembro de 1999, período em que se intensificam as trocas de dados, propostas e idéias, além do estabelecimento das condições contratuais para a efetivação da cooperação. Por fỉm, o terceiro estágio se inicia em janeiro de 2000, quando é assinado pelas partes um termo aditivo ao contrato formal, que oficializa a pesquisa cooperativa e se encerra em janeiro de 2002, quando vence o contrato estabelecido.

Motivações à cooperação também podem ser notadas na preocupação da empresa com o desenvolvimento de tecnologias para a redução do consumo de energia e a possibilidade de contar com a capacitação universitária para esse desenvolvimento, o que reduziria seus custos de pesquisa e forneceria acesso à mão-de-obra altamente qualificada, além da estrutura existente na universidade. Por parte do laboratório observou-se como motivador a necessidade de recursos adicionais, a melhor utilização do equipamento existente e a maior interação com o mercado, o que representou uma das etapas necessárias ao seu crescimento e amadurecimento no processo que o conduziu ao estágio de laboratório dinâmico, experiente e bem estruturado que é hoje.

Duas barreiras observadas ocorreram no princípio da cooperação. Uma resultante do posicionamento de um coordenador que não percebeu a natureza distinta das parceiras e as especificidades que isso cria no processo. A segunda, em face da necessidade de se conhecerem melhor as partes, para ampliação da confiança e também pelo desenvolvimento de uma linguagem comum, essa dificuldade deixou o processo um pouco mais lento em seu início, mas os óbices foram vencidos posteriormente. O papel do governo como facilitador pode também ser claramente identificado no caso estudado, pois a obtenção de recursos, com 
a aprovação de projeto pelo o Programa RHAE (Recursos Humanos em Áreas Estratégicas) do CNPq, ampliou a capacitação do laboratório e demonstrou o reconhecimento governamental em seu esforço e habilitação para pesquisa; mas é preciso ressaltar como facilitadora, frisada até pelos entrevistados, a realização do curso de mestrado por engenheiros da empresa na PUCPR, dentro do LST, pois isso promoveu maior facilidade de comunicação, entrosamento e aproximação tanto dos objetivos como do ambiente acadêmico e empresarial.

Do mesmo modo, o caso apresentado permite observar parcialmente as novas considerações relativas à cooperação U-E encontradas na literatura. No estudo desenvolvido foi possível perceber a ocorrência da terceira missão da universidade, isto é, ser agente do desenvolvimento regional, que é uma das modificações conceituais que conduziram ao que Noveli (2006) denomina de Tripla Hélice III. O desempenho desse papel está presente na cooperação em estudo na própria relevância de seu objeto de pesquisa, em face do contexto nacional apresentado, porquanto, além de propor melhorias em produtos que causam impacto em setor estratégico da economia nacional (a energia), a pesquisa assegurou maior competitividade a uma indústria situada na mesma cidade e Estado que a universidade, promovendo o desenvolvimento econômico regional. Isso também parece ter contribuído para a redução das dificuldades presentes na natureza distinta das instituições parceiras, uma vez que, parafraseando Sutz (1997), a visão das universidades por empresas e governos como instituições devotadas ao bem nacional da competitividade econômica, mais do que ao bem universal do conhecimento, tende a diminuir os limites entre academia e indústria, à medida que vai sendo socialmente aceita, tanto que, apesar das indagações feitas aos entrevistados, nenhuma das partes conseguiu identificar nenhum outro momento ou processo de conflito durante a cooperação, muito menos problemas ou dificuldades que tenham tomado proporções de maior relevância.

Na parte relativa à intermediação, a existência de um setor, o ICET (Instituto de Ciências Exatas e da Tecnologia) na PUCPR, facilitou principalmente a questão burocrática, por já ter desenvolvido o chamado contrato guarda-chuva. Como instrumento, foi utilizado o Termo Aditivo, que funcionaria como acordo formal com alvo definido, considerando os instrumentos citados no referencial teórico apresentado.

O estudo demonstrou o uso de diferentes formas de interação U-E para consolidação da cooperação como o financiamento de pesquisas científicas da universidade pela empresa; a prestação de serviços da universidade para a empresa; a relação pessoal formal por meio da realização de curso na universidade por funcionários da empresa; e a própria pesquisa realizada conjuntamente. 
A transferência do conhecimento se deu por meio de reuniões, relatórios, programas computacionais entregues à empresa, e participação de engenheiros da empresa no programa de mestrado da instituição. Esse último merece novo comentário adicional, ao representar uma adequação às necessidades e propostas da pesquisa conjunta, pois garantiu também melhor assimilação da tecnologia a ser transferida, ao qualificar melhor a mão-de-obra da empresa para a recepção do conhecimento criado, facilitando a linguagem comum das partes e promovendo o maior entrosamento das equipes.

Os resultados da cooperação podem ser observados principalmente nos produtos obtidos, isto é, três programas computacionais (PAS, SIAS e FRIGUS) dos trabalhos realizados, mais de 80 ensaios de consumo de energia, relatórios técnicos (três relatórios técnicos internos totalizando mais de 450 páginas), cinco dissertações de mestrado defendidas e artigos publicados em anais de eventos científicos. Outros resultados precisam ser também considerados, como a inovação incremental desenvolvida, isto é, o aperfeiçoamento da eficiência energética do produto, o conhecimento transmitido e a qualificação da mão-de-obra.

Além disso, ficam claras as vantagens obtidas pelos participantes. A empresa obteve nova tecnologia que permite simulações que reduzem seus custos de pesquisa e ampliam a vantagem competitiva de seus produtos, ao torná-los mais eficientes no tocante ao consumo energético, principalmente em momento em que a economia de energia se tornou questão estratégica para a manutenção e ampliação de vendas no setor de eletrodomésticos. A universidade obteve os recursos adicionais necessários ao seu laboratório e a satisfação do desenvolvimento de um instrumento tecnológico que atende às necessidades do mercado brasileiro, considerando a relevância atual para o Brasil de estudos voltados para a redução do consumo de energia. E, por fim, os mestrados desenvolvidos na PUCPR pelos cinco engenheiros da Electrolux demonstram ainda a existência de vantagens comuns às partes em processos de cooperação universidade-empresa, pois esses mestrados foram estimulados pela pesquisa cooperativa descrita neste trabalho.

Desse modo, pode-se perceber no estudo da experiência dessas instituições uma cooperação tecnológica, a produtividade e eficiência do trabalho cooperativo universidade-empresa; cumpre ressaltar o fato de ser essa uma relação cooperativa entre uma instituição acadêmica privada e uma empresa, uma vez que a maioria dos casos descritos na bibliografia nacional se refere a cooperações realizadas entre universidades públicas e empresas.

Ressalte-se ainda que, principalmente em face do contexto energético mundialmente instalado, avanços tecnológicos voltados para redução de consumo de energia não apenas representam preciosas vantagens competitivas para a 
empresa e sua atuação conjunta com o meio científico universitário garante seu posicionamento na vanguarda de seu setor, como também possui relevante papel social, pois um estudo de conservação de energia elétrica em refrigeradores pode auxiliar na redução da necessidade de elevados investimentos em geração ou em importação de energia, diminuindo os riscos de black-out e, conseqüientemente, trazendo benefícios para a sociedade em termos de conforto e qualidade de vida.

\section{Artigo recebido em 20.09.2005. Aprovado em 14.12.2005.}

\section{Referencias Bibliográficas}

Alem, A. C.,

Barros, J. R. M., \&

Giambiagi, F. (2002).

Bases para uma política industrial moderna. Anais do Fórum Nacional do Instituto Nacional de Altos Estudos, Rio de Janeiro, RJ, Brasil, 14.

Boehe, D. M., \&

Zawislak, P. A. (2005).

Os papéis das subsidiárias localizadas no Brasil na estratégia de desenvolvimento de produto de empresas multinacionais. Anais do Seminário Latino-Iberoamericano de Gestión Tecnológica - ALTEC, Salvador, BA, Brasil, 11.

Chaimovich, H. (1999, outubro/dezembro). Por uma relação mutuamente proveitosa entre universidade de pesquisa e empresas. Revista de Administração da USP, 34(4), 18-22.

Etzkowitz, H. (1998, December).

The entrepreneurial university and the emergence of the democratic corporatism. In H. Etzkowitz (Org.). The norms of entrepreneurial science: cognitive effects of the new universityindustry linkages. Research Policy, 27(8), 823-833.
Etzkowitz, H. (2003, January).

Research groups as 'quasi-firms': the invention of the entrepreneurial university. Research Policy, 32(1), 109-121.

Etzkowitz, H., \&

Leydesdorff, L. (1997a, February).

Introduction to special issue on science policy: dimensions of the triple helix of University-industrygovernment relations. Science and Public Policy, 24(1), 2-5.

Etzkowitz, H., \&

Leydesdorff, L. (Orgs). (1997b).

Universities and the globlal knowledge economy: a triple helix of university-industry-government relations. New York: Continuum.

Etzkowitz, H., \&

Leydesdorff, L. (2000, February).

The dynamics of innovation: from national systems and "mode 2 " to a triple helix of university-industrygovernment relations. Research Policy, 29(2), 411-424. 
Etzkowitz, H.,

Mello, J. M. C., \&

Almeida, M. (2005, May).

Towards "meta-innovation" in Brazil: the evolution of the incubator and the emergence of the triple helix. Research Policy, 34(4), 109-123.

Flores, M. J., \&

Segatto-Mendes, A. P. (2005)

Contribuições da cooperação universidade - empresa para a capacitação tecnológica de PME’s moveleiras do pólo de Arapongas. Anais do Seminário LatinoIberoamericano de Gestión Tecnológica - ALTEC, Salvador, BA, Brasil, 11.

Fujino, A.,

Stal, E., \&

Plonski, G. A. (1999, outubro/dezembro).

A proteção do conhecimento na universidade. Revista de Administração da USP, 34(4), 46-55.

Gaynor, G. H. (2002).

Innovation by design: what it takes to keep your company on the cutting edge. New York: AMACOM.

Gomes, C. M., \&

Kruglianskas, I. (2005).

O processo de gestão de fontes externas de inovação em empresas industriais. Anais do Seminário Latino-Iberoamericano de Gestión Tecnológica, Salvador, BA, Brasil, 11.

Hall, R. H. (2004).

Organizações - Estruturas, processos e resultados (8a ed., pp. 191-222). São Paulo: Pearson/Prentice Hall.
Johnston, R. E., Jr., \&

Bate, J. D. (2003).

The power of strategy innovation: a new way of linking creativity and strategic planning to discover great business opportunities. New York: AMACOM.

Lastres, H. M. M. (1997, outubro).

A Globalização e o Papel das Políticas de Desenvolvimento Industrial e Tecnológico. (Texto para Discussão $N^{\circ}$ 519). Convênio Ministério do Planejamento e Orçamento - IPEA/CEPAL. Brasília.

Levy, C. (2005, setembro 2 a 8).

Lei da inovação já tramita no congresso. Jornal da Unicamp, (188), pp. 6-7. Pesquisa e Desenvolvimento. Recuperado em 13 agosto, 2005, de http://www.unicamp.br/unicamp/ unicamp_hoje/jornalPDF/188pag06.pdf

Noveli, M. (2006).

Cooperações Universidade-empresa em parques tecnológicos: o caso Tecnopuc. Dissertação de Mestrado. Centro de Pesquisa e Pós-Graduação em Administração/CEPPAD, UFPR, Curitiba, PR, Brasil.

Organization for Economic Co-operation and Development - OECD (2000).

A new economy? the changing role of innovation and information technology in growth. Paris: Author. 
Pereira, J. M., \&

Kruglianskas, I. (2005).

Políticas de fomento à inovação: as fragilidades da lei de inovação tecnológica do Brasil. Anais do Seminário Latino-Iberoamericano de Gestión Tecnológica, Salvador, BA, Brasil, 11.

Plonski, G. A. (1994).

Cooperação empresa-universidade na ibero-américa: estágio atual e perspectivas. Anais do Simpósio de Gestão da Inovação Tecnológica, São Paulo, SP, Brasil, 18.

Plonski, G. A. (1995).

Cooperacion empresa-Universidad en Iberoamerica: estágio atual e perspectivas. In G. A. Plonski (Ed.). Cooperacion empresa-universidad en Iberoamerica: avances recentes. São Paulo: CYTED.

Plonski, G. A. (1999, outubro/dezembro). Cooperação universidade-empresa: um desafio gerencial complexo. Revista de Administração da USP, 34(4), 5-12.

Raposo, M. L.,

Serrasqueiro, Z. (2005, abril/junho).

A universidade e o desenvolvimento regional. Cadernos de Economia, (71), pp. 100-104. Recuperado em 24 setembro, 2005, de http:// www.cadernoseconomia.com.pt/ ce71/mario_lino_raposo.pdf

Rogers, E. (2003).

Diffusion of innovations (5a ed.). New York: Free Press.

Sbragia, R. (1994).

A experiência da universidade de São
Paulo. Revista Ciência, entrevista em São José - Costa Rica.

\section{Selltiz, C.,}

Wrigutsmann, L., \&

Cook, S. (1974).

Métodos de pesquisa nas relações sociais (3a ed.) São Paulo: Herder.

Segatto, A. P. (1996).

Análise do processo de cooperação tecnológica universidade - empresa: um estudo exploratório. Dissertação de Mestrado. Faculdade de Economia, Administração e Contabilidade, USP, São Paulo, SP, Brasil.

Segatto-Mendes, A. P. (2001).

Teoria de agência aplicada à análise de relações entre os participantes dos processos de cooperação tecnológica universidade-empresa. Tese de Doutorado. Faculdade de Economia, Administração e Contabilidade, Universidade de São Paulo, SP, Brasil.

Segatto-Mendes, A. P., \&

Sbragia, R. (2002, outubro/dezembro).

$\mathrm{O}$ processo de cooperação universidade-empresa em universidades brasileiras. Revista de Administração da USP, 37(4), 58-71.

Sutz, J. (1997).

The new role of university in the productive sector. In. H. Etzkowitz \& L. Leydesdorff (Orgs.). Universities and the global knowledge economy: a triple helix of university-industrygovernment relations (pp. 11-20). New York: Continumm. 
Sutz, J. (2000, February).

The university-industry-government relations in Latin America. Research Policy, 29(2), 279-290.

Stal, E. (1997).

Centros de pesquisa cooperativa: um modelo eficaz de interação universidade-empresa. Tese de Doutorado. Faculdade de Economia, Administração e Contabilidade, USP, São Paulo, SP, Brasil.

Stal, E., \&

Fujino, A. (2005).

Aprimorando as relações Universidade-Empresa-Governo no Brasil: a lei de inovação e a gestão da propriedade intelectual. Anais do Seminário Latino-Iberoamericano de Gestión Tecnológica, Salvador, BA, Brasil, 11.

Vedovello, C. (1997).

Science park and university-industry interaction: geographical proximity between the agents as a driving force. Technovation, 17(9), 491-502.

Vedovello, C. (1998, July).

Firms' R\&D activity and intensity and the university-enterprise partnerships. Technological Forecasting and Social Change, 58(3), 215-226. 